\title{
Modelling and analyzing spatial clusters of leptospirosis based on satellite-generated measurements of environmental factors in Thailand during 2013-2015
}

\author{
Amornrat Luenam, ${ }^{1}$ Nattapong Puttanapong ${ }^{2}$ \\ ${ }^{1}$ Faculty of Public and Environmental Health, Huachiew Chalermprakiet University, Samut Prakan; \\ ${ }^{2}$ Faculty of Economics, Thammasat University, Khlong Luang, Thailand
}

\begin{abstract}
This study statistically identified the association of remotely sensed environmental factors, such as Land Surface Temperature (LST), Night Time Light (NTL), rainfall, the Normalised Difference Vegetation Index (NDVI) and elevation with the incidence of leptospirosis in Thailand based on the nationwide 7,495 confirmed cases reported during 2013-2015. This work also established prediction models based on empirical findings. Panel regression models with random-effect and fixed-effect specifications were used to investigate the association between the remotely sensed environmental factors and the leptospirosis incidence. The Local Indicators of Spatial Association (LISA) statistics were also applied to detect the spatial patterns of leptospirosis and similar results were found (the $R^{2}$ values of the random-effect and fixed-effect models were 0.3686 and 0.3684 , respectively). The outcome thus indicates that remotely sensed environmental factors possess statistically significant contribution in predicting this disease. The highest association in 3 years was observed in LST (random-effect coefficient $=-9.787, \mathrm{P}<0.001$; fixed-effect coefficient $=-10.340, \mathrm{P}=0.005$ ) followed by rainfall (random-effect coefficient $=1.353, \mathrm{P}<0.001$; fixed-effect coefficient $=1.347, \mathrm{P}<0.001$ ) and NTL density (random-effect coefficient $=-0.569, \mathrm{P}=0.004$; fixed-effect coefficient $=-0.564, \mathrm{P}=0.001)$. All results obtained from the bivariate LISA statistics indicated the localised associa-
\end{abstract}

Correspondence: Amornrat Luenam, Faculty of Public and Environmental Health, Huachiew Chalermprakiet University, Samut Prakan, 10540, Thailand.

Tel.: +66.089.112.2289.

E-mail: luenam.hcu@gmail.com

Key words: Satellite data; remote sensing; leptospirosis; spatial clusters; Thailand.

Received for publication: 8 January 2020

Accepted for publication: 22 August 2020.

(C) Copyright: the Author(s), 2020

Licensee PAGEPress, Italy

Geospatial Health 2020; 15:856

doi:10.4081/gh.2020.856

This article is distributed under the terms of the Creative Commons Attribution Noncommercial License (CC BY-NC 4.0) which permits any noncommercial use, distribution, and reproduction in any medium, provided the original author(s) and source are credited. tions between remotely sensed environmental factors and the incidence of leptospirosis. Particularly, LISA's results showed that the border provinces in the northeast, the northern and the southern regions displayed clusters of high leptospirosis incidence. All obtained outcomes thus show that remotely sensed environmental factors can be applied to panel regression models for incidence prediction, and these indicators can also identify the spatial concentration of leptospirosis in Thailand.

\section{Introduction}

Leptospirosis, which has been a major public health problem in Thailand for decades, is caused by spirochete bacteria of the genus Leptospira (WHO, 2003), that can be transmitted to humans from many mammal carriers, such as livestock, dogs and rodents. Thailand is considered a tropical country as the yearly temperatures range from $23^{\circ} \mathrm{C}$ to $33^{\circ} \mathrm{C}$. This condition is conducive for the propagation of Leptospira in many mammals and therefore increases vector density, e.g., of rats, which facilitates the rapid spread of leptospirosis. However, leptospirosis is common in most tropical countries. Dhewantara et al. (2019) report that the occurrence of leptospirosis in China is positively associated with rainfall. In Indonesia, excessive rainfalls have led to flooding and affected puddle formation, depending on the type of soil in the area (e.g. clay soils) and the presence of water inundation (Sunaryo and Widiastuti, 2012). In South Pacific Island, moisture can gradually accumulate in the soil, which promotes leptospirosis growth (Lau et al., 2012). Thus, people in tropical areas are exposed to leptospirosis during their agricultural activities. In addition, rainfall is associated with epidemics in humans and animals through the water contaminated with the urine of infected animals.

In the case of Thailand, a total of 7,495 leptospirosis cases were reported from 2013 to 2015 . The annual average number of infections was 4.83, 3.47 and 3.30 for 2013, 2014 and 2015, respectively (MoPH, 2006). Although the number of reported cases has decreased, epidemics remain a serious concern (Gonwong et al., 2017; Hinjoy, 2014). Leptospirosis outbreaks most likely occur in the northeast, northern and southern regions. The disease is markedly seasonal and has a varied intensity of transmission because of environmental factors. The risk of leptospirosis epidemics is the highest during June-December, and the peak outbreak occurs in October (Luenam and Puttanapong, 2019).

Leptospirosis epidemics are influenced by several conditions, such as certain occupations, flooding and vigour of the rodent population (Diaz, 2015). Moreover, transmission is affected by many climatic and environmental factors (Haake and Levett, 2015). Scholars have focused on predicting leptospirosis epidemics by using satel- 
lite-based environmental indicators at various spatial and temporal scales because remote-sensing technology provides a broad range of useful physical environmental data (Herbreteau et al., 2007). Rainfall is an environmental factor that affects this infection among humans and animals (Triampo et al., 2007; Chadsuthi et al., 2012). It is also associated with the slope and movement of surface water (Lau et al., 2012; Gracie et al., 2014). Night Time Light (NTL) has commonly been used as a proxy of urban density and applied in epidemiological studies (Henderson et al., 2012; Li et al., 2016a; Gao et al., 2015; Li et al., 2016b). In Thailand, the NTL index has been utilised as a proxy of population density, and the NTL concentration is highly correlated with the incidence of chronic respiratory diseases (Laohasiriwong et al., 2018).

Empirically, epidemiological studies have demonstrated that leptospirosis arises in different geographic areas (Luenam and Puttanapong, 2019). Musa et al. (2013) used Geographic Information Systems (GISs) and other tools for geographic pattern analysis. Furthermore, Anselin (1995) introduced a then new computational technique and emphasised the advantage of Local Indicators of Spatial Association (LISA) in epidemiological studies. In Thailand, Luenam and Puttanapong (2019) conducted the spatial and statistical analyses of leptospirosis during 2013-2015 using LISA to analyse its spatial distribution. Similarly, Laohasiriwong et al. (2018) used this approach to perform spatial autocorrelation and hotspot analyses of chronic respiratory disease epidemics.

The lack of adequate, ground-based environmental data is a great constraint for developing a supporting system for the epidemiological control of leptospirosis and the development of a prediction model. Alternatively, GIS-based data gathering methods and satellite-based environmental data offer substantial advantages, such as the large-area coverage and continuous spatio-temporal representation of the Earth's surface (Adeola et al., 2019). The previously conducted leptospirosis studies in Thailand used conventional environmental data rather than satellite-based environmental indicators despite the considerable potential of the latter. In addition, the spatial cluster analysis of diseases, particularly at the national level, has rarely been applied to investigate the geographical characteristics of leptospirosis.

This study aimed at using satellite-based environmental data to identify spatial association and develop a prediction model by integrating satellite data and spatial cluster analysis. Specifically, satellite-based environmental factors (i.e. NTL, Land Surface Temperature (LST), rainfall, elevation and the Normalised Difference Vegetation Index (NDVI) were combined with the statistics of leptospirosis incidence from the nationwide geospatial dataset. LISA statistics was used to detect the spatial correlation patterns of leptospirosis in terms of bivariate between leptospirosis and satellite-based environmental factors in Thailand during 20132015 to quantitatively examine the associations. In addition, both specifications of panel regression techniques, namely, fixed-effect and random-effect estimations, were utilised to develop prediction models.

\section{Materials and methods}

\section{Study area and seasons}

This study focused on Thailand, which has an area of 514,000 $\mathrm{km}^{2}$ that comprises $511,770 \mathrm{~km}^{2}$ of land and 2,230 $\mathrm{km}^{2}$ of water.
The country has 77 provinces, 878 districts (amphoes), 7,225 subdistricts (tambons) and 74,965 villages (moobans). There are three seasons: winter from November to February, summer from March to May and a rainy season from June to October.

\section{Data sources}

This longitudinal study used the incidence of leptospirosis per 100,000 people from 2013 to 2015 as reported by the Centre of Epidemiological Information, Bureau of Epidemiology, Ministry of Public Health. The data included the number of cases for all 77 provinces in the country with a total of 7,495 cases distributed over the study period. The data are publicly available at the National Disease Surveillance's website (MoPH, 2006). Officially, the criterion of being infected by this type of bacteria is defined as having had leptospirosis clinically diagnosed previously by a physician. The diagnostic codes used for the infection are A27.0-A27.9 of the International Statistical Classification of Diseases and Related Health Problem, 10th Revision (ICD-10). The satellite-based environmental factors included NTL, LST, rainfall, elevation and NDVI. All variables were aggregated at the provincial level to match the spatial resolution of leptospirosis incidence.

The NTL data of Thailand from 2013 to 2015 were acquired from the Visible Infrared Imaging Radiometer Suite's Day-Night Band global stable light imagery at a spatial resolution of 375 $\mathrm{m}^{2} /$ pixel. All NTL light data are publicly available (NOAA, 2019). Elevation data were derived from the National Aeronautics and Space Administration (NASA)'s Shuttle Radar Topographic Mission 90-metre Digital Elevation Data, which provides global elevation data and is publicly available (NASA, 2019). The monthly rainfall statistics (January 2013-December 2015) were obtained from the Topical Rainfall Measuring Mission (TRMM)-3B43 dataset produced by NASA's Goddard Earth Sciences Data and Information Services Centre. Monthly accumulated precipitation data were generated from the Rainfall Estimate L3 1-month TRMM (TMPA/3B43) at a spatial resolution of $0.25^{\circ} \times 0.25^{\circ}$ (TRMM, 2011). The monthly LST statistics from the moderate resolution imaging spectroradiometer (MODIS) satellite (MOD11C3) with a $1 \mathrm{~km}$ spatial resolution (Wan, 2007) were used as a proxy for temperature. The NDVI data from MODIS satellite (MOD13Q1) with a 250-m spatial resolution were also used in this analysis. These satellite-based environmental indicators were aggregated to compute for the annual mean at the provincial level to match the spatial resolution of leptospirosis incidence.

\section{Data analysis}

\section{Panel regression}

As stated by Hsiao (2007), panel regression has the advantages of yielding a more accurate inference of model parameters, as well as capturing the embedded individual characteristics. Therefore, this study used the panel regression to estimate the relationship between the environmental factors and leptospirosis incidence whilst simultaneously capturing the magnitudes of province-specific effects.

The yearly incidence of leptospirosis in the 77 provinces was modelled with statistical 'panel regression' in Stata, version 10.0 by using random-effect and fixed-effect specifications. A natural $\log$ transformation was used to linearize variations in all variables. The multivariate models were fitted with log-transformed leptospirosis cases in association with satellite-based environmental data. All variables with a P-value of less than 0.25 were included 
in the multivariate modelling. Backward elimination was used for variable selection to obtain the final model. A $p$-value $<0.05$ was considered statistically significant. All statistical tests were twosided. Equations 1 and 2 express the panel regression models with fixed-effect and random-effect specifications, respectively (TorresReyna, 2007).

$Y_{i t}=\beta_{1} \operatorname{lnLST}_{i t}+\beta_{2} \operatorname{lnRainfall}_{i t}+\beta_{3} \operatorname{lnNTL}_{i t}+\beta_{4} \operatorname{lnNDVI}_{i t}+\beta_{5}$ lnElevation $_{i t}+\alpha_{i}+u_{i t}$

where $Y_{i t}=$ the dependent variable (leptospirosis incidence); $i=$ entity (77 provinces); $t=$ time (2013-2015); $\beta_{1}, \beta_{2}, \beta_{3}, \beta_{4}, \beta_{5}=$ the coefficients for satellite-based environmental indicators; $\alpha_{i}=$ the intercept for each entity (the $i$ entity-specific intercepts); and $u_{i t}=$ the error term.

$Y_{i t}=\beta_{1} \operatorname{lnLST}_{i t}+\beta_{2} \operatorname{lnRainfall}_{i t}+\beta_{3} \operatorname{lnNTL}_{i t}+\beta_{4} \operatorname{lnNDVI}_{i t}+\beta_{5}$ lnElevation $_{i t}+\alpha+u_{i t}+\varepsilon_{i t}$

where $Y_{i t}=$ the dependent variable (leptospirosis incidence); $i=$ entity (77 provinces); $t=$ time (2013-2015); $\beta_{1}, \beta_{2}, \beta_{3}, \beta_{4}, \beta_{5}=$ the coefficients for satellite-based environmental indicators; $\alpha=$ the intercept term; $u_{i t}=$ the between-entity error; and $\varepsilon_{i t}=$ the withinentity error.

\section{LISA analysis}

Leptospirosis patterns were detected on the basis of the localised detection of prevalent spatial patterns. For exploratory spatial data analysis, QGIS, version 3.8.3 (Steiniger and Hunter, 2013) and GeoDa, version 1.12.1.161 were applied to determine the measure of spatial autocorrelation analysis (Anselin et al., 2006). QGIS was used to integrate all data before transferring to GeoDa for LISA analysis.

The spatial autocorrelation statistic (Moran's $I$ ) is one of the main techniques for quantifying the degree of spatial correlation (Moran, 1950). The following equation represents the computational formula of Moran's I test:

Moran's $I=\left(\mathrm{N} \Sigma_{i} \Sigma_{j} \mathrm{~W}_{i j}\left(\mathrm{~A}_{i}-\overline{\mathrm{A}}\right)\left(\mathrm{A}_{j}-\overline{\mathrm{A}}\right)\right) /\left(\Sigma_{i} \Sigma_{j} \mathrm{~W}_{i j} \Sigma_{i}\left(\mathrm{~A}_{i}-\overline{\mathrm{A}}\right)^{2}\right)$

where $\mathrm{A}_{i}=$ the variable of interest; $\mathrm{N}=$ the number of spatial units indexed by $i$ and $j ; \mathrm{W}_{i j}=$ the spatial weight matrix; $\mathrm{A}_{i}-\overline{\mathrm{A}}=$ the deviation of from $\mathrm{A}_{i}$ its mean; and $\mathrm{A}_{j}-\overline{\mathrm{A}}=$ the deviation of $\mathrm{A}_{j}$ from its mean. The computed value indicates the correlation between $A$ located in area $i$ and its neighbours geographically defined by the spatial weight matrix $\left(\mathrm{W}_{i j}\right)$.

Moran's $I$ has a limitation in identifying the location of correlation. Hence, the local Moran I or LISA, has been developed by extending the mathematical fundamental of Moran's $I$. Its mathematical representation is shown as follows:

Local Moran $I_{i}=\left(\mathrm{A}_{i}-\overline{\mathrm{A}}\right) \Sigma_{j} \mathrm{~W}_{i j}\left(\mathrm{~A}_{j}-\overline{\mathrm{A}}\right) / \mathrm{s}_{i}^{2}$

where $\mathrm{s}_{i}^{2}=\Sigma_{j}\left(\mathrm{~A}_{j}-\overline{\mathrm{A}}\right)^{2} /(\mathrm{N}-1) ; \mathrm{W}_{i j}=$ the spatial weight matrix; and $\mathrm{N}=$ the number of spatial units.

The obtained output is the indicator of Moran's $I$ at each location $i$, which indicates the correlation between the value of $\mathrm{A}$ in area $i$ and that of its neighbours. Based on the fundament of the statistical correlation test, this value can identify positive and negative associations.
The selection of the spatial weight matrix is one of the key factors contributing to the outcome of LISA computation; thus, its specification has been carefully formulated in this study. Given that Thailand comprises one island province together with 23 coastal provinces and 32 border ones, the spatial weight matrix of $3 \mathrm{k}$-nearest neighbour was used to optimise the sufficient number of neighbouring provinces and maintain the localised characteristic. The results of LISA generated a Moran's $I$ index along with the cluster map and the $p$-value one. The cluster map indicates fivecolour schemes, with high-high delegated as dark red (hotspots), low-low as dark blue (coldspots), low-high as light blue, highlow as pink and the random pattern as white (Anselin, 2003). Statistically, the cases of high-high, low-low, low-high and highlow are statistically significant areas of spatial correlations, and the white area represent the case of no spatial correlation. Particularly, the hotspots (high-high areas) indicate the statistically high incidence of leptospirosis, whereas the coldspots (low-low areas) imply a statistically low incidence. The cases of high-low and low-high ones identify the negative correlation between particular provinces and their neighbours.

As shown by Anselin (1995), the LISA analysis is capable of conducting univariate and bivariate tests of spatial correlation. In bivariate LISA, the analysis is extended to examine the localised association between two variables. With this extension, the outcome of bivariate LISA indicates the correlation between a variable at a specific location and the corresponding spatial lag (i.e. the average computed over the surrounding areas) of the other variable. In this study, bivariate tests were conducted to verify the spatial correlation between each satellite-based environmental indicator and the incidence of leptospirosis.

\section{Results}

Table 1 shows the comparison of the predicted leptospirosis cases with the random-effect and fixed-effect models. The obtained outcomes indicate that NTL, LST and rainfall were associated with the incidence of leptospirosis $(\mathrm{P}<0.05)$. Specifically, LST showed the highest association in all 3 years (coefficient $=$ 9.787, $\mathrm{P}<0.001 \&-10.340, \mathrm{p}=0.005$ ) with respect to random-effect and fixed-effect, respectively, followed by rainfall (coefficients = $1.353, \mathrm{P}<0.001 \& 1.347, \mathrm{P}<0.001$ ) and NTL (coefficients $=-0.569$, $\mathrm{P}=0.004 \&-0.564, \mathrm{P}=0.001)$. The estimated random-effect and fixed-effect models explained approximately $36.9 \%$ and $36.8 \%$ of the variation in leptospirosis, respectively (Table 1). These outcomes identified that LST and NTL were negatively associated with the incidence of leptospirosis. The higher magnitudes of LST and NTL implied a high concentration of buildings and concrete surfaces, which attenuate the probability of leptospirosis outbreaks. By contrast, rainfall was positively correlated with the incidence of leptospirosis. This empirical relationship indicated that an increase in rainfall induces a suitable environmental for a leptospirosis epidemic.

The outcomes of the bivariate LISA identified the statistically substantial positive correlation of rainfall, elevation and NDVI with the leptospirosis hotspots, whereas NTL and LST had a negative spatial correlation with a potential leptospirosis incidence. All Moran's $I$ values for 2013, 2014 and 2015 were significant at $\mathrm{P}<0.05$ (Table 2 and Figures 1-5).

The results of the bivariate LISA tests for the cluster maps of all 3 years show that each pair of satellite-based environmental fac- 
tors (rainfall, elevation, NDVI, NTL and LST) and leptospirosis incidence indicated similar clusters of hotspots and coldspots. These outcomes, based on the types of remote sensing data utilized (Figures 1-5), affirm the consistent spatial patterns in many areas of Thailand. Particularly, the hotspots imply the localised positive association between the enabling environmental factors and the higher incidence of leptospirosis. The coldspots identify the localised negative correlation between the satellite-based indicators and the incidence of leptospirosis. The provinces with hotspot clusters were mostly located in the southern part of the country, particularly in the coastal region, because of their proximities to the equator and the higher frequency of rainfall. In addition, there were hotspot clusters for elevation located in the northern part, while those for NDVI were mostly located in the southern and northern regions. On the contrary, the coldspot clusters for NTL and LST were mostly located in the central areas, where urbanisation has been expanding.

\section{Discussion}

Conventionally, the assessment of adverse health effects related to satellite-based environmental factors often involves an analysis of different geographical and temporal scales to project the actual risk accurately. In this study, we utilised panel regression models obtained from all regions in Thailand to investigate the association of such factors with the incidence of leptospirosis. Satellite-based environmental factors were selected based on a $\mathrm{P}$-value $<0.05$, which represent the correlations of leptospirosis incidence with rainfall, NTL and LST during 2013-2015. Skouloudis and Rickerby (2015) supported a similar finding and revealed that the global occurrence of leptospirosis is negatively associated with NTL and LST.

The satellite-based environmental data are essential determinants of leptospirosis epidemics, and the findings obtained in this study are consistent with previous studies of temperature and rainfall. The LST, i.e., affects the potential spread of leptospirosis by shortening the extrinsic incubation period of Leptospira within the vector carrier and increases its rate of survival in temperatures ranging from $4{ }^{\circ} \mathrm{C}$ to $40^{\circ} \mathrm{C}$ (Parker and Walker, 2011), while the correlation between researchers (Triampo et al., 2007; Chadsuthi et al., 2012; Ledien et al., 2017). One paper (Skouloudis and Rickerby, 2015) indicates that torrential rainfall increases the size of epidemics through indirect transmission from contaminated water after flooding in tropical countries.

Similar to other satellite-based environmental indicators, the NTL plays a crucial role in identifying the spatial cluster of leptospirosis. Globally, the NTL density has been used as a proxy of growth in provinces as a representation of population density, economic growth and urban expansion (Henderson et al., 2012; Li, 2016a). The areas with high leptospirosis morbidity rates experience a low growth in NTL; thus, the high concentration of NTL

Table 1. Estimated parameters obtained from panel regression (fixed \& random effect) for predicting leptospirosis incidence during 2013-2015.

\begin{tabular}{lcc} 
Independent variable & Panel regression (random effect) & Panel regression (fixed effect) \\
Constant & 9.849 & 10.656 \\
& $(\mathrm{P}<0.000)$ & $(\mathrm{P}=0.005)$ \\
LST & -9.787 & -10.340 \\
& $(\mathrm{P}<0.000)$ & $(\mathrm{P}=0.005)$ \\
\hline Rainfall & 1.353 & 1.347 \\
NTL & $(\mathrm{P}<0.000)$ & $(\mathrm{P}<0.000)$ \\
& -0.569 & -0.564 \\
NDVI & $(\mathrm{P}=0.004)$ & $(\mathrm{P}=0.001)$ \\
& -0.554 & -0.576 \\
Elevation & $(\mathrm{P}=0.119)$ & $(\mathrm{P}=0.199)$ \\
& -0.016 & -0.026 \\
\hline R-Squared & $(\mathrm{P}=0.523)$ & $(\mathrm{P}=0.796)$
\end{tabular}

P-value $=0.05$ as threshold level of statistical significance. Dependent variable: provincial incidence of leptospirosis.

Table 2. The bivariate Moran's I of incidence of leptospirosis during 2013-2015.

\begin{tabular}{|c|c|c|c|}
\hline Remotely sensed variables & & ran's I & \\
\hline & 2013 & 2014 & 2015 \\
\hline LST & -0.456 & -0.258 & -0.334 \\
\hline Rainfall & 0.254 & 0.406 & 0.213 \\
\hline NTL & -0.459 & -0.313 & -0.337 \\
\hline NDVI & 0.338 & 0.261 & 0.361 \\
\hline Elevation & 0.435 & 0.285 & 0.309 \\
\hline
\end{tabular}

P-value $=0.05$ as threshold level of statistical significance. 
density implies a lowered incidence of leptospirosis. In Thailand, the rural agricultural areas include some provinces in the north, north-eastern and southern regions, where the main occupation is rice farming (Triampo et al., 2007). In addition, Thai agricultural workers are highly exposed to biological contaminants in the environment (Chadsuthi et al., 2012). Therefore, the NTL index can indicate the spatial density of agricultural sectors through the low degree of brightness in lighted areas. Although the panel regressions' results reported here do not indicate that elevation is associated with the incidence of leptospirosis, the outcome obtained from LISA confirms the localised correlation of both variables. As studied in China and Indonesia, the main causes of this association were the direct contact of abraded skin with contaminated water or soil and the limited availability of health services at highlands

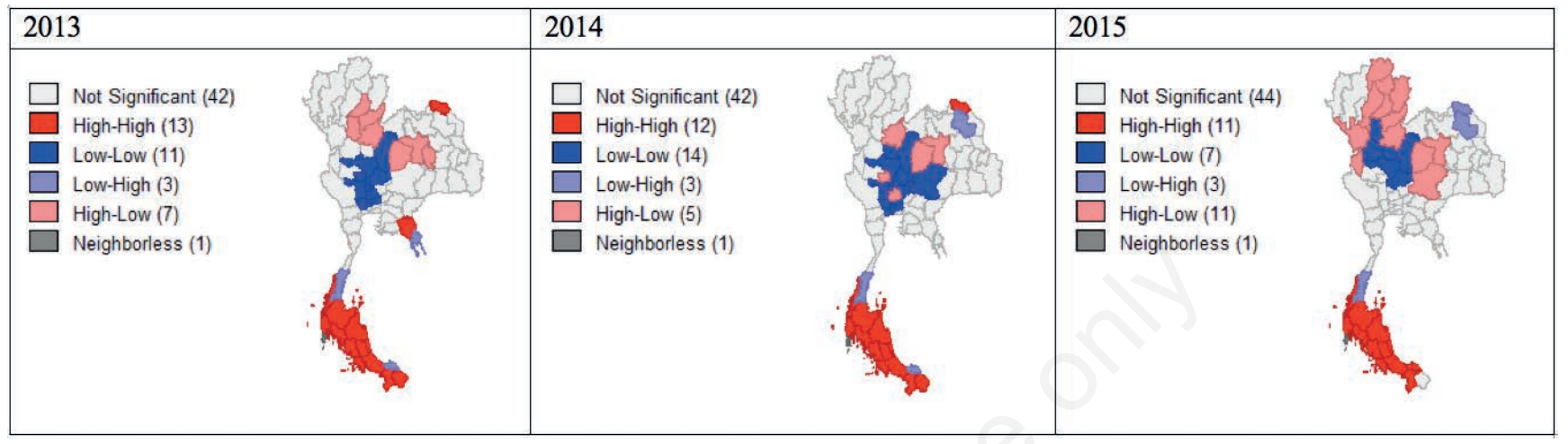

Figure 1. LISA cluster maps of bivariate analyses: rainfall and incidence of leptospirosis during 2013-2015.

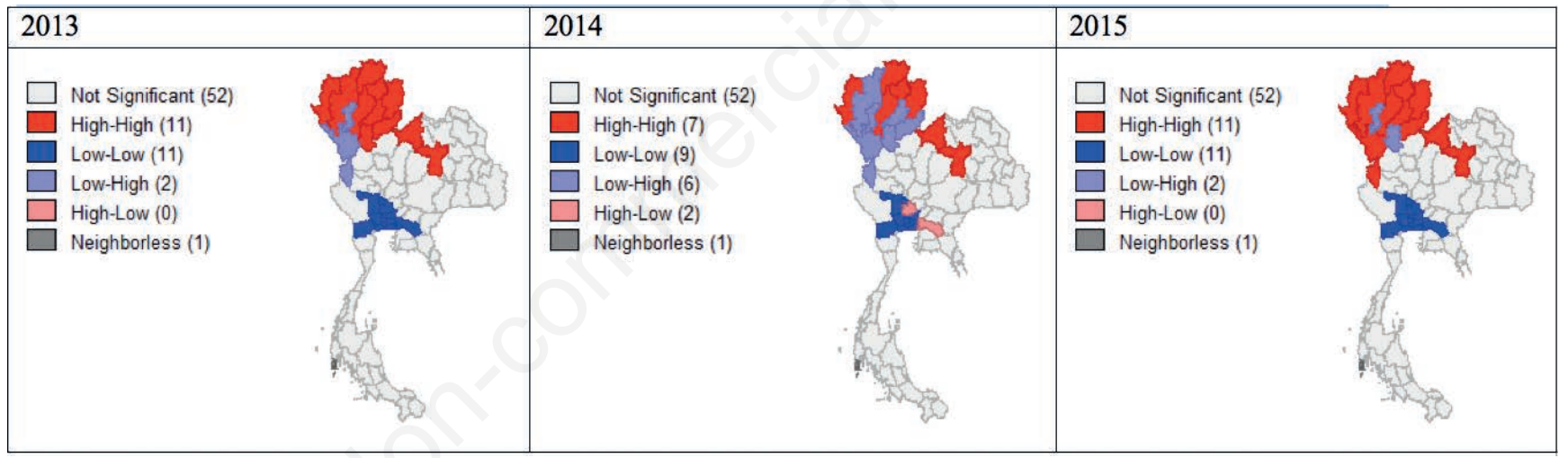

Figure 2. LISA cluster maps of bivariate analyses: elevation and incidence of leptospirosis during 2013-2015.

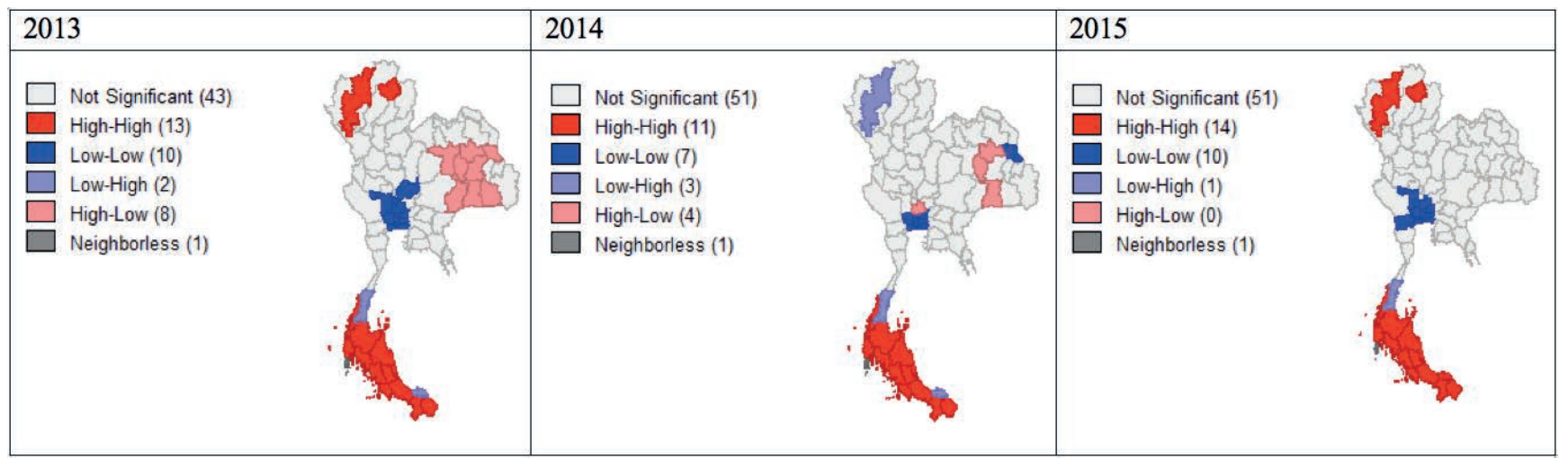

Figure 3. LISA cluster maps of bivariate analyses: NDVI and incidence of leptospirosis during 2013-2015. 
(Basnyat et al., 2001; Sunaryo and Widiastuti, 2012; Dhewantara et al., 2020). Similar to the case of elevation, the panel regressions rejected the association between NDVI and leptospirosis incidence. However, the LISA's outcome statistically identified the positive correlation between NDVI and leptospirosis hotspots. Similar to the findings of Herbreteau et al. (2006), the value of NDVI is positively associated with the incidence of leptospirosis. NDVI represents the density of chlorophyll (e.g. areas of forests and cultivation activities). Therefore, the high NDVI index also indicates an increasing chance of leptospirosis exposure.

LISA is a spatial statistical tool used for investigating the local clusters of diseases and assessing their statistical impact (Anselin, 2004). LISA is proven effective in spatial pattern analysis because it can accurately classify high-rate and low-rate leptospirosis regions. In this study, LISA was employed to explore the correlation between satellite-based environmental factors and the incidence of leptospirosis. Hotspot areas can dynamically fluctuate because of variations in environmental factors; thus, the satellitebased indicators can potentially serve as alternative data sources for the timely detection of leptospirosis hotspot clusters.

The results obtained from both panel regression methods do not indicate the statistically significant influence of elevation and NDVI on the incidence of leptospirosis, although the outcomes generated by LISA identify such relationships. This difference is caused by the difference in technical foundations. The panel regressions examined the association between environmental factors and leptospirosis incidence in a particular province (i.e. intraprovincial relationship). On the contrary, LISA investigated the correlation between the leptospirosis incidence in a particular province and the average of environmental indicators in surrounding areas (i.e. the inter-provincial influence). Hence, the interpretation of results should be carefully undertaken along with the awareness of the advantages and limitations of each methodology.

This study has some limitations. Firstly, the models developed for incidence prediction were limited to other environmental risk factors, such as land use, humidity and soil type, which were not explored but may be required to characterise the infection risk of leptospirosis. Secondly, social factors, such as population migration, were not included because of data limitations. These factors could influence the identification of high-risk areas and help improve our model. Hence, further studies should be conducted to expand the inclusion of additional social and environmental risk factors.

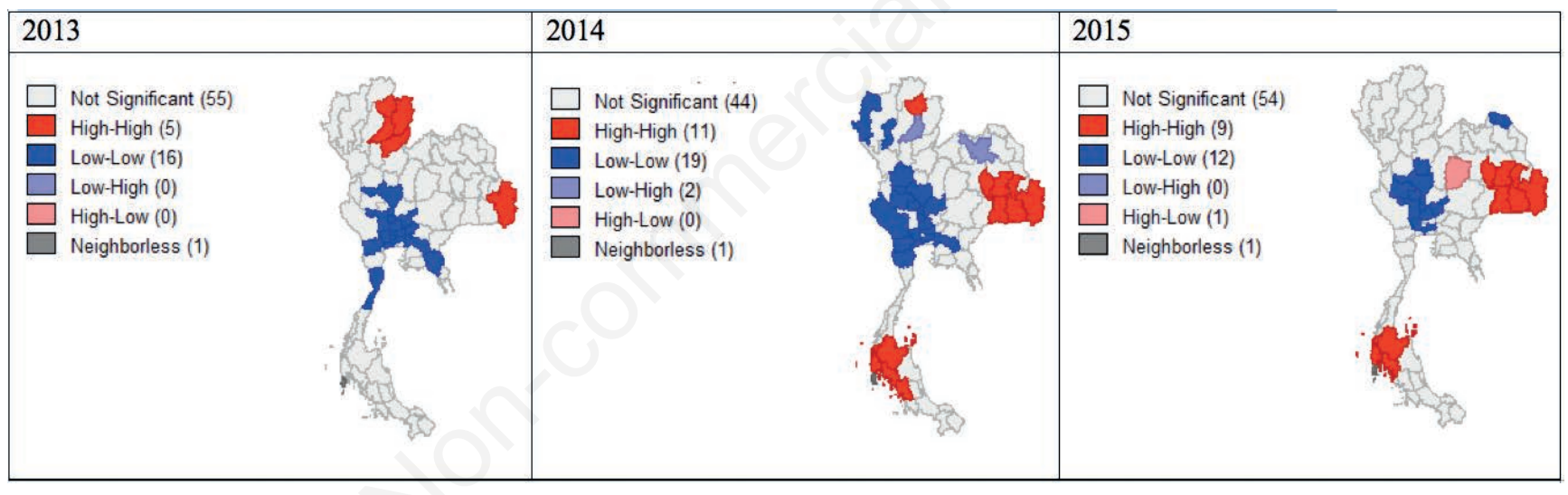

Figure 4. LISA cluster maps of bivariate analyses: NTL and incidence of leptospirosis during 2013-2015.

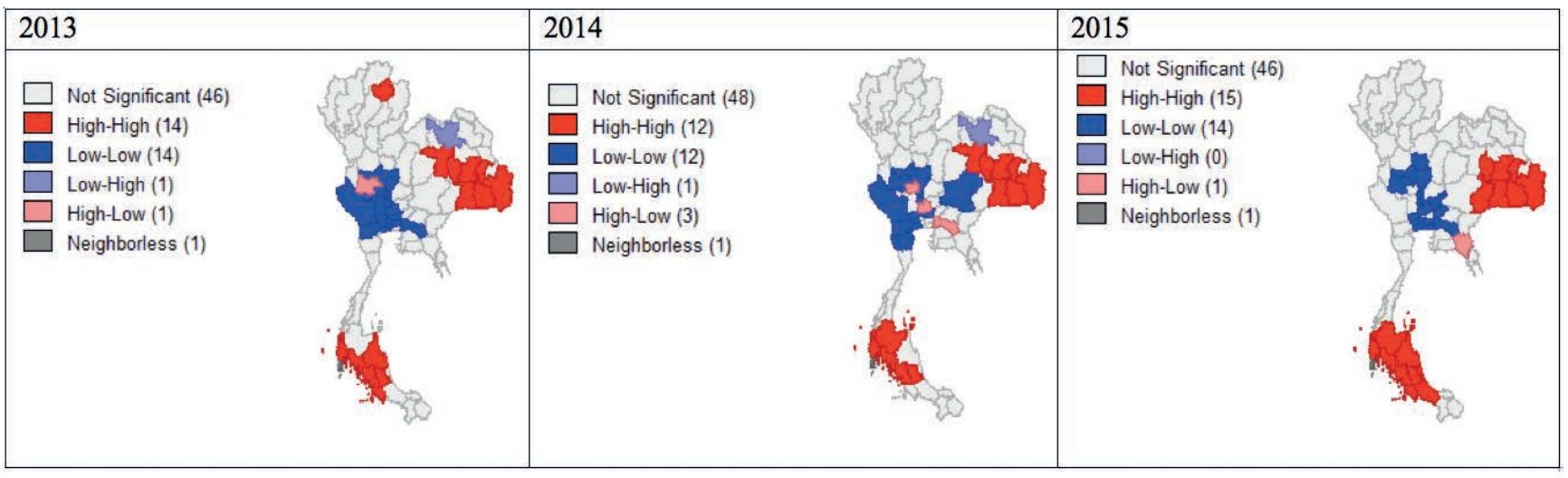

Figure 5. LISA cluster maps of bivariate analyses: LST and incidence of leptospirosis during 2013-2015. 


\section{Conclusions}

The results obtained from LISA indicate that the outcome from a consistent dataset of LST, NTL, rainfall, NDVI and elevation for 2013-2015 is statistically associated with leptospirosis incidence, whereas the panel data regressions show that the subsets of LST, NTL and rainfall are remarkably correlated with leptospirosis incidence and can serve as the main indicators for determining leptospirosis hotspots. The results obtained from panel regressions indicate that satellite-based environmental factors could be used for assessing the temporal dependence of leptospirosis incidence. These findings can be applied as a prototype for furthering the development of an early warning model based on timely satellitebased environmental factors. These outcomes also provide a basis for planning public health prevention programmes for leptospirosis with relevance to the environmental context.

\section{References}

Adeola A, Botai JO, Olwoch JM, de W. Rautenbach H, Adisa OM, et al., 2019. Predicting malaria cases using remotely sensed environmental variables in Nkomazi, South Africa. Geospat Health 14:81-91.

Anselin L, 1995. Local Indicators of Spatial Association (LISA). Geogr Anal 27:93-115.

Anselin L, 2003. An introduction to spatial autocorrelation analysis with GeoDa. Spatial Analysis Laboratory, University of Illinois. Available from: https://personal.utdallas.edu/ $\sim$ briggs/poec6382/geoda_spauto.pdf

Anselin L, 2004. Review of Cluster Analysis Software. The North American Association of Central Cancer Registries, Inc. Available from: https://www.naaccr.org/wp-content/uploads/ 2016/11/Final-Report-Cluster-Software-2004-09-27-rev.pdf

Anselin L, Syabri I, Kho Y, 2006. GeoDa: an introduction to spatial data analysis. Geogr Anal 38:5-22.

Basnyat B., Cumbo TA, Edelman R, 2001. Infections at high altitude. Clin Infect Dis 33:1887-91.

Chadsuthi S, Modchang C, Lenbury Y, Iamsirithaworn S, Triampo W, 2012. Modeling seasonal leptospirosis transmission and its association with rainfall and temperature in Thailand using time-series and ARIMAX analyses. Asian Pac J Trop Med 5:539-46.

Dhewantara PW, Hu W, Zhang W, Yin W, Ding F, et al., 2019. Leptospirosis, Climate and Satellite-based Environmental Factors: A Temporal Modeling. Online J Public Helath Info 11:e396.

Dhewantara PW, Zhang W, Al Mamun A, Yin WW, Ding F, et al., 2020. Spatial distribution of leptospirosis incidence in the Upper Yangtze and Pearl River Basin, China: Tools to support intervention and elimination. Sci Total Environ 725:138251.

Diaz JH, 2015. Rodent-borne infectious disease outbreaks after flooding disasters: Epidemiology, management, and prevention. Am J Disaster Med 10:259-67.

Gao B, Huang Q, He C, Ma Q, 2015. Dynamics of urbanization levels in China from 1992 to 2012: Perspective from DMSP/OLS nighttime light data. Remote Sens 7:1721-35. doi:10.3390/rs70201721

Gracie R, Barcellos C, Magalhães M, Souza-Santos R, Barrocas PRG, 2014. Geographical scale effects on the analysis of lep- tospirosis determinants. Int $\mathrm{J}$ Environ Res Public Health 11:10366-83.

Haake DA, Levett PN, 2015. Leptospirosis in humans. Curr Top Microbiol Immunol 387:65-97.

Henderson JV, Storeygard A, Weil DN, 2012. Measuring economic growth from outer space. Am Econ Rev 102:994-1028.

Herbreteau V, Demoraes F, Khaungaew W, Hugot JP, Gonzalez JP, et al., 2006. Use of geographic information system and remote sensing for assessing environment influence on leptospirosis incidence, Phrae province, Thailand. Int J Geoinformatics 2:43-50.

Herbreteau V, Salem G, Souris M, Hugot JP, Gonzalez JP, 2007. Thirty years of use and improvement of remote sensing, applied to epidemiology: from early promises to lasting frustration. Health Place 13:400-3.

Hinjoy S, 2014. Epidemiology of leptospirosis from Thai national disease surveillance system, 2003-2012. OSIR 7:1-5. Available from: http://www.osirjournal. net/index.php/osir/ article/ view/38

Hsiao, C, 2007. Panel data analysis - advantages and challenges. TEST 16:1-22.

Gonwong S, Chuenchitra T, Khantapura P, Islam D, Ruamsap N, et al., 2017. Nationwide seroprevalence of leptospirosis among young Thai men, 2007-2008. Am J Trop Med Hyg 97:1682-5.

Laohasiriwong W, Puttanapong N, Luenam A, 2018. A comparison of spatial heterogeneity with local cluster detection methods for chronic respiratory diseases in Thailand. F1000Res 6:1819. doi: 10.12688/f1000research.12128.2

Lau CL, Clements ACA, Skelly C, Dobson AJ, Smythe LD, Weinstein P, 2012. Leptospirosis in American Samoa - estimating and mapping risk using environmental data. PLoS Negl Trop Dis 6:e1669. doi:10.1371/journal.pntd.0001669

Ledien J, Sorn S, Hem S, Huy R, Buchy P, et al., 2017. Assessing the performance of remotely-sensed flooding indicators and their potential contribution to early warning for leptospirosis in Cambodia. PloS ONE 12:e0181044. doi:10.1371/ journal. pone. 0181044

Li D, Zhao X, Li X, 2016a. Remote sensing of human beings-a perspective from nighttime light. Geo Spat Inf Sci 19:69-79. doi:10.1080/10095020.2016.1159389

Li Q, Lu L, Weng Q, Xie Y, Guo H, 2016b. Monitoring urban dynamics in the southeast USA using time-series DMSP/OLS nightlight imagery. Remote Sens 8:578.

Luenam A, Puttanapong N, 2019. Spatial and statistical analysis of leptospirosis in Thailand from 2013 to 2015. Geospat Health 14:121-7.

Ministry of Public Health (MoPH), 2006. National Disease Surveillance 2000-2006. The War Veterans Organization of Thailand. Available from:https://hdcservice.moph.go.th/hde/ main/index.php\#

Moran PAP, 1950. Notes on continuous stochastic phenomena. Biometrika 37:17-23.

Musa GJ, Chiang P-H, Sylk T, Bavley R, Keating W, et al., 2013. Use of GIS mapping as a public health tool: from cholera to cancer. Health Serv Insights 6:111-6.

NASA, 2019. Shuttle Radar Topographic Mission 90-metre Digital Elevation Data. Available from: http://srtm.csi.cgiar.org/

National Oceanic and Atmospheric Administration (NOAA), 2019. National Centers for Environmental Information. Version 1 VIIRS day/night band nighttime lights. Available from: https://www. ngdc.noaa.gov/ eog/viirs/download_dnb_composites.html 
Parker J, Walker M, 2011. Survival of a pathogenic Leptospira serovar in response to combined in vitro $\mathrm{pH}$ and temperature stresses. Vet. Microbiol 152: 146-50.

Skouloudis AN, Rickerby DG, 2015. In-situ and remote sensing networks for environmental monitoring and global assessment of leptospirosis outbreaks. Procedia Eng 107:194-204.

Steiniger S, Hunter AJ, 2013. The 2012 free and open source GIS software map: A guide to facilitate research, development, and adoption. Comput Environ Urban Syst 39:136-50.

Sunaryo S, Widiastuti D, 2012. Mapping of leptospirosis risk factor based on remote sensing image in Tembalang, Semarang City, Central Java. Health Sci J Indones 3:45-50. Available from: https://media.neliti.com/media/publications/61779-ENmapping-of-leptospirosis-risk-factor-bas.pdf

Torres-Reyna O, 2007. Panel data analysis fixed and random effects using Stata (v. 4.2). Data \& Statistical Services, Priceton University. Available from: https://www.princeton. edu/ otorres/Panel101.pdf
Triampo W, Baowan D, Tang I, Nuttavut N, Wong-Ekkabut J, et al., 2007. A simple deterministic model for the spread of leptospirosis in Thailand. Int J Bio Med Sci 2:22-6.

TRMM, 2011. TRMM_3B43: TRMM (TMPA/3B43) Rainfall estimate L3 1 month 0.25 degree x 0.25 degree V7. NASA Earth Data - GES DISC. doi:10.5067/TRMM/TMPA/MONTH/7 Available form: https://disc.gsfc.nasa.gov/datasets/ TRMM 3B43_7/summary

Wan Z, 2007. Collection-5 MODIS land surface temperature products usersguide. ICESS, University of California, Santa Barbara. Available from: https://www.researchgate.net/publication/267547661_Collection-5_MODIS_Land_ Surface_Temperature_Products_Users $\% 27$ _ Guide

WHO, 2003. Human leptospirosis: guidance for diagnosis, surveillance and control. Available from: https://www.who.int/publications/i/item/human-leptospirosis-guidance-for-diagnosissurveillance-and-control 